\title{
Cognition investigation and analysis of hand hygiene of nursing staff in pension institutions
}

\author{
Bing Yu, Yujin Liu ${ }^{a}$, Wenjing Sun, Xiufeng Zhao, Zhuang Cong and Wei Meng \\ Welfare College of Nursing of College of Humanities\&Northeast Normal University, 130117, Changchun, China
}

\begin{abstract}
Objective: We investigate and analyze the cognition of hand hygiene of nursing staff in nursing institutions. This method provides reference for improving the hand hygiene condition of nursing staff in nursing homes, and we put forward the feasible solution to this situation. Methods: 100 nurses from five nursing institutions in Changchun were investigated using a self-designed questionnaire, and the results were analyzed. Results: due to the most oldage care institutions personnel are less educated, rapid flow of talents, and the health care training from endowment organization are low frequency or not organized, so most of nursing staff think hand hygiene has nothing to do with the health of the elderly. They grasp the knowledge of some common hand washing, and hand washing before and after the elderly care is not ideal. The effects of hand washing have a number of factors, the main factor is that the pension institutions hand washing facilities incomplete, and in fact the nursing staff work very busy. Discussion: from the government to pension institutions should strengthen and pay more attention to the training of pension agency front-line care staff hand hygiene knowledge, increase the training of professional nursing practitioners, focus on bringing in Colleges and universities social science or medical science related, similar professional personnel and institutional strengthening management of washing hands, according to the actual conditions to improve the hand washing facilities, adhere to wash their hands properly, so as to avoid occurrence of handling of disease spread.
\end{abstract}

\section{Introduction}

With the increasing of the aging of the population in China, nearly one million employees in China more than 40000 social welfare institutions, nursing staff is the largest group of [1], constitute the main force in the industry. Nursing staff during routine care for the elderly, often to help the old man eating drinking water and the old man's body surface skin, waste and old man around various objects surface contact, resulting in nursing staff hand carrying a variety of pathogenic bacteria. Nurses and contact with the elderly opportunity most longest contact time, the old resistance strength is low, if the before and after nursing activities without enough opponent cleaning or disinfection, it is easy to cause hand the spread of pathogens to the next An old man and infection diseases affect health, even the old man one of the causes of death. In the hospital, the hospital environment and the surfaces of various

\footnotetext{
${ }^{a}$ Corresponding author: Liu Yujin, E-mail:1257819211@qq.com
}

This work was Supported by a Social Sciences planning project of Department of Education of Jilin Province(2014.12.1). 
objects exist lots of microorganisms, the hands of medical workers in a variety of clinical operation inevitably often contact the microbial contamination and become the potential factors of nosocomial infection. Studies have shown that the hands of medical personnel in the spread of bacteria and the occurrence of hospital infection accounted for about 30\%[2], therefore, hand contamination of medical staff is an important route of transmission of the hospital infection caused by. Cleaning and disinfection of hand skin is very important, and wash it the most simple and feasible to control the hospital infection measures. Public places Hand hygiene is to prevent infection diseases of important means, in the developing world hand hygiene can significantly reduce the outbreak of the disease in children. Good hand hygiene habits can effectively prevent diarrhea and respiratory diseases, such as infectious diseases. However, the residents of China proper hand washing rate is only $4 \%$ [3]. based on the above, in access to a large number of documents at the same time, there are no about nursing home care personnel hand hygiene cognition survey report, this paper on nursing home care hand hygiene knowledge were investigated.

\section{Objects and methods}

\subsection{Research objects}

A questionnaire survey was conducted on 100 nurses in eight nursing homes in Changchun city.

\subsection{Survey methods}

According to the World Health Organization of $<$ medical and health institutions guideline for hand hygiene $>$ and China's $2009<$ medical staff hand hygiene practices > file based, designed the "endowment nursing staff hand hygiene cognition questionnaire. The questionnaire is divided into four parts: the first part is the basic information survey, including unit, position, seniority, sex, marriage, education. The second part is nursing staff opponents hygiene knowledge to grasp the situation. The third part is the nursing staff in the correct way to wash your hands to grasp the situation. The fourth part is factor of the effects of hand washing[4].

\subsection{Statistical methods}

All data were collected and analyzed by SPSS17.0 statistical software. The descriptive statistical method was used.

\section{Results and analysis}

\section{1 analysis of the general situation of nursing staff}

100 nurses, including 12 male and 88 female people; More than 2 years over the age of 45; 1058291 100 nursing, male 12 , female 88 people, 30 - 40, 22, 41 - 50 years of age 45,51 years old and above 33 people, and the seniority in the following 32 people, length of $1-2$ years 43 people, age 2 years above 25 people; cultural degree: elementary school, junior high school, high school, college and above 3 people ': urban laid-off workers, migrant workers 30 people. The results of the survey show that pension institutions nursing personnel age mainly concentrated in 41, urban laid-off workers and migrant workers. Personnel flow, length of service is only 25 people, so to him The training needs to be targeted, training frequency should be repeated, so that it changes the concept. 


\subsection{The analysis of nursing staff on hand indications}

From Table 1 can see nursing staff to contact with the old man's blood, body fluids, secretions, mucous membrane, incomplete skin wash to the indications for $100 \%$ is much higher than the other hand washing indications, showing that self protection consciousness is strong. Wash your hands after contact with the elderly around objects to indications minimum was $23 \%$, and protection of the elderly, to prevent cross infection awareness is weak, and nurses cultural degree low, ID thought, nor did he accept any hand hygiene knowledge, there are many relationships.

Table 1. The analysis of nursing staff on hand indications

\begin{tabular}{|c|c|c|c|}
\hline Choice of indications for hand washing or hand disinfection & Need & Unwanted & Correct rate \\
\hline Visible blood stains or by hands, body fluids contaminated dirt & 100 & 0 & $100 \%$ \\
\hline Direct contact with an old man's body before & 45 & 55 & $45 \%$ \\
\hline $\begin{array}{c}\text { After each contact an old man intact skin (such as the measurement of } \\
\text { vital signs, patient handling, help) }\end{array}$ & 65 & 35 & $65 \%$ \\
\hline $\begin{array}{c}\text { To assist the elderly taking oral medicine, eating, drinking water before } \\
\text { and after }\end{array}$ & 54 & 46 & $54 \%$ \\
\hline $\begin{array}{c}\text { Exposed to the old man's mucous membrane, after the skin is not } \\
\text { complete }\end{array}$ & 100 & 0 & $100 \%$ \\
\hline $\begin{array}{c}\text { After the body fluid, the secretion, the secretion or the secretion after } \\
\text { the dressing of the old man }\end{array}$ & 100 & 0 & $100 \%$ \\
\hline $\begin{array}{c}\text { In the process of nursing for the elderly, the hand from the old man's } \\
\text { body to clean parts before the Department of pollution }\end{array}$ & 76 & 24 & $76 \%$ \\
\hline After each contact with an old man around the object & 23 & 77 & $23 \%$ \\
\hline $\begin{array}{c}\text { Do you need to wash your hands before and after wearing gloves } \\
\text { (including disposable gloves and non disposable gloves) }\end{array}$ & 32 & 68 & $32 \%$ \\
\hline After meals & 80 & 20 & $80 \%$ \\
\hline
\end{tabular}

\subsection{Analysis of nursing staff's health related knowledge mastery}

Department of nursing staff opponents of bacteria related knowledge mastery is $10 \%$, the six step hand washing method is $4 \%$. See Table 2 , which shows that the nursing staff opponents of health related knowledge master level rate is low, opponents of health knowledge, there is no complete system learning.

Table 2.Analysis of nursing staff's health related knowledge mastery

\begin{tabular}{|c|c|c|c|}
\hline Project & Correct & Not correct & Correct rate \\
\hline $\begin{array}{c}\text { Bacteria parasitic on the hand are mainly divided into temporary } \\
\text { and resident bacteria. }\end{array}$ & 4 & 96 & $4 \%$ \\
\hline
\end{tabular}




\begin{tabular}{|c|c|c|c|}
\hline $\begin{array}{c}\text { The main hand bacteria causing nosocomial infection were resident } \\
\text { bacteria. }\end{array}$ & 10 & 90 & $10 \%$ \\
\hline $\begin{array}{c}\text { Hand washing is mainly in order to remove the hand of the resident } \\
\text { bacteria }\end{array}$ & 9 & 91 & $9 \%$ \\
\hline $\begin{array}{c}\text { If the gloves are not obviously contaminated, do not need to be } \\
\text { replaced for other patient services }\end{array}$ & 35 & 65 & $35 \%$ \\
\hline October 15th is the international day of washing" & 2 & 98 & $2 \%$ \\
\hline $\begin{array}{c}\text { Do you usually wash your hands in accordance with the six steps of } \\
\text { washing }\end{array}$ & 4 & 96 & $4 \%$ \\
\hline Does soap need to be kept dry & 24 & 76 & $24 \%$ \\
\hline Care for more than one elderly, whether the need to replace gloves & 34 & 66 & $34 \%$ \\
\hline Disposable gloves may be reused & 45 & 55 & $45 \%$ \\
\hline Before using the "fast hand", you need to keep your hands dry. & 17 & 83 & $17 \%$ \\
\hline
\end{tabular}

\subsection{Factors influencing hand washing of nursing staff}

The main factors that affect the hand washing of nursing staff are busy, not enough time, the rate is $96 \%$, followed by the forgotten in what situations should wash their hands, the rate is $94 \%$, the specific Table 3.

Table 3.Factors influencing hand washing of nursing staff

\begin{tabular}{|c|c|c|c|}
\hline Project & Yes & No & Influence rate \\
\hline Cleaning agent, disinfectant to stimulate the skin, causing dry skin & 91 & 9 & $91 \%$ \\
\hline $\begin{array}{c}\text { The number of hand washing pool is too small in the working } \\
\text { environment. }\end{array}$ & 87 & 13 & $87 \%$ \\
\hline $\begin{array}{c}\text { The position of hand washing pool is not convenient in working } \\
\text { environment. }\end{array}$ & 90 & 10 & 90 \\
\hline $\begin{array}{c}\text { Hand wash basin is not equipped with enough cleaning agent } \\
\text { Hand wash basins are not equipped with dry hand facilities (such as } \\
\text { disposable hand towels, sterile towels or dryer, etc.) }\end{array}$ & 67 & 33 & $67 \%$ \\
\hline $\begin{array}{c}\text { Liquid soap, hand disinfection, dry toilet paper costs too high } \\
\text { Work too busy, not enough time }\end{array}$ & 65 & 35 & $86 \%$ \\
\hline The risk of being contaminated by a nurse is very low. & 76 & 24 & $76 \%$ \\
\hline
\end{tabular}




\begin{tabular}{|c|c|c|c|}
\hline $\begin{array}{c}\text { Person to hand washing or hand disinfection in the work is not enough } \\
\text { attention }\end{array}$ & 88 & 12 & $88 \%$ \\
\hline Forgot to wash hands under what conditions & 94 & 6 & $94 \%$ \\
\hline
\end{tabular}

\section{Discussion}

The nurses completed, pension institutions service quality depends on the nursing staff to take care of the elderly is special. Hand hygiene as nurses for the elderly to implement each service operation premise, has very important significance. The investigation shows, nursing staff on hand to hand hygiene knowledge and related sign is not clear, the understanding is superficial, to wash the finger and hand hygiene related knowledge has a lot of mistakes, influence of nursing staff and the wash factors affect the rate was above $65 \%$. Hand washing behavior is a complex phenomenon, hindering handwashing behavior factors is multi-level, there are internal and external causes in the pension institutions all care activities for the elderly, involving the environment, cognitive, interactions between many of the emotional level factors. Reason analysis for China's pension institutions started late, for the elderly health management lacking, for the fine service to do does not reach the designated position. Pension institutions may did not do a good job of nursing personnel training and health propaganda work, the local government while carrying out the pre service system, but the training is not standardized, as far as the training requirements. From the point of view of management and there is no understanding in hand hygiene of importance and neglect the opponents of health management. In institution endowment nursing staff general cultural quality low, high school degree or above $13 \%$ of nursing staff in the loss of serious, length of service 2 years above is only a community service center in Beijing 25\%[5]. 2005 had free training more than 100 laid-off personnel, but after a lapse of one year has no people in nursing jobs. High turnover rate, affecting the normal work of old-age care institutions, and even the some pension agencies did not dare to implement strict management of nursing staff. Age generally are relatively large, than younger people have more experience of life and experience, work conscientiously, steadfast. But in this age of cultural quality of personnel is low, has formed inherent mode of thinking and living habits, difficult to change the mode of thinking and bring personal lifestyle and health habits to work, in an Hand hygiene related theoretical knowledge of poor ability. In the wash factors, mainly pension institutions hand washing facilities are not complete, the nursing staff workload. Factors of hand hygiene behavior is multifaceted, it is result of personnel and the surrounding environment interact continuously, even including psychology, habits, and from the perspective of behavioral science to analysis, knowledge is the premise that belief structures, but faith will guide a person's behavior[6]. Based on the above reasons, first of all, should accelerate the old-age nursing team construction, along with the development of the aging of the population and the old social welfare undertakings, China needs a large number of high-quality nursing staff, enhancing the nursing staff treatment, which is to speed up the building of the contingent of the key. Vigorously develop professional workers, should pay attention to the introduction of special talent for pension institutions, nursing staff and the introduction should focus on Colleges and universities social science or medical science related, similar professional personnel. Secondly, increased government support and investment in infrastructure, implement preferential policies and help pension institutions to reduce construction and operating costs, improve the environment and facilities, and satisfy the basic needs of the front-line staff. Again, a strong proponent of nursing staff in nursing homes in the health of continuing education, the government of the nursing personnel implement free training to endowment organization training or care Professionals themselves to spend money training - at least for now, reality, the implementation of government funded free training, improve the quality of personnel, pension institutions overall level of health services can be improved[7]. Finally, the government should strengthen supervision and management, who hand washing facilities non-compliance, should warn rectification; pension institutions should also be to strengthen their own management, improve hand washing facilities, 
urging nursing staff to establish a habit of hand hygiene, convenient wash, dry hands, hand measures is to ensure that all effective hand washing, a prerequisite to enhance awareness of nursing staff hand washing; pension institutions can post corresponding publicity column or a photograph in the old room or corridor, to promote nursing staff to develop a good hand Health habits, while obtaining the understanding of the elderly[8].

In short, hand washing is one of the most simple and easy way to prevent and control the spread of pathogens is an important measure to prevent the elderly from being infected with infectious diseases, but also the effective means of two-way protection of elderly nursing staff and the elderly.

\section{References}

1. The Ministry of civil affairs. China Civil Affairs statistical yearbook. Beijing: China Statistics Press(2009).

2. Yang Shuping. Investigation and Analysis on cognitive behavior of nursing students to wash hands and Countermeasures. nursing practice and research,6, 21(2009).

3. Leaf Daxun. Wash your hands. A simple but meaningful measures, the British Medical Journal (Chinese Edition),3(2000).

4. A white paper on hand washing status of residents in the Ministry of health of the Ministry of healt,10(2011).

5. WHO advisory panel and WHO Advisory Committee and hand hygiene program drafting group hand hygiene guidelines for medical and health institutions - WHO - hand hygiene guidelines in medical activities(2005).

6. Huang Juru, Zhong Chunjiao, Xiao Fenglan et al. Investigation of hand washing behavior of nurses. Journal of nosocomial infection in China,14,12(2004).

7. Chen Zhuoyi, Chen Wei, present situation and Countermeasures of the construction of nursing staff in China. Journal of Changsha District Vocational Technical College, 12,16(2009).

8. Yuan Xiaoning, Wang Shaoli, Zhao Xinmao et al. Investigation and Analysis on the knowledge and behavior of the hand hygiene of the hospital assistant staff. The nursing management in China,4,8(2008). 